\title{
Improving upon Bogardus: Creating a More Sensitive and Dynamic Social Distance Scale
}

Darin M. Mather, Stephen W. Jones ${ }^{\dagger}$, Scott Moats ${ }^{\ddagger}$

Tags: sensitivity measures, scaling, bogardus social distance scale

DOI: $10.29115 /$ SP-2017-0026

\section{Survey Practice}

Vol. 10, Issue 4, 2017

Since 1925, the Bogardus Social Distance Scale has been a staple in social science research. This scale, which is often used to study prejudice and intergroup relations, asks participants to self-disclose their feelings of acceptance for members of out-groups. Ranging from 1 (no social distance) to 7 (greatest social distance), the scale measures respondents' perceived sense of intimacy or closeness to those in groups that are different from their own. This study shows the utility of adding a unique intensity score (iScore) dimension to the Bogardus scale by combining it with a Likert scale to produce a new measure. This improved measure provides a greater level of precision, sensitivity, and nuance than the traditional Bogardus Social Distance Scale. The study offers a direct comparison of the traditional Bogardus and new iScore results. Findings demonstrate the advantages of using an iScore.

\section{INTRODUCTION}

In the 1920s, Bogardus (1926) pioneered a series of studies on social distance, which he defined as "the degree of sympathetic understanding that functions between person and person, between person and group, and between groups" (Bogardus 1959, p. 7). In this line of research, which is widely influential to this day [see Ethington (1997) and Parrillo and Donoghue (2005) for a review], scholars are concerned with the degree to which a respondent views members of a different group as acceptable or objectionable. The Bogardus Social Distance Scale asks respondents to report whether they would relate to members of an out-group in a variety of ways ranging from "accepting them as close relatives by marriage" to "excluding them from my country." Responses are placed on a scale and each tested group's rank on the continuum provides an indication of the degree of intimacy the respondent feels toward members of that group. Results are used to determine which groups in a society are more socially close and distant (Parrillo and Donoghue 2005). These findings are then employed to uncover linkages between social distance and prejudice, hostility, discrimination, and other social phenomenon (cf., Halperin et al. 2007; Weaver 2008).

\footnotetext{
* Institution: Crown College

† Institution: Crown College

$\ddagger$ Institution: Crown College
} 
The Bogardus scale is a powerful tool that has been used for decades to advance social scientific understanding. However, because of the nature of the scale, it is not as precise, sensitive, and nuanced as it could be. In this study, we argue that social distance is better measured using an intensity score (iScore). This approach is simple to use like the traditional Bogardus method, but it provides improved results.

In the paragraphs that follow, we provide a brief description of the Bogardus Social Distance Scale, the standard social scientific tool for measuring social distance. Next, we present the iScore method, highlighting its difference from the Bogardus scale. The paper concludes with direct comparisons between the Bogardus and iScore scales to demonstrate the improved performance of the iScore across a range of potential social distance responses.

\section{SOCIAL DISTANCE SCALES}

The Bogardus Social Distance Scale employs Guttman's rank order scaling system to measure the perceived social distance between individuals, particularly those in racial and ethnic groups. Guttman's binary scale (1950) arranges items in an order so that an individual who agrees with an item also agrees with items of lower rank-order. The items on the binary list suggest that if one of the higher order questions were true, then all the lower items would be true also.

Bogardus applies this method using a series of seven prompts to assess whether people would be willing to interact with members of select groups in the following ways:

- As close relatives by marriage (score 1.00$)$

- As close personal friends (2.00)

- As neighbors on the same street (3.00)

- As co-workers in the same occupation (4.00)

- As citizens in my country (5.00)

- As only visitors in my country (6.00)

- Would exclude from my country (7.00)

Responses to the above statements provide a measure of the perceived distance between groups, with lower scores indicating less social distance and a greater sense of intimacy between the respondent and the named group. Respondents who would accept members of a select group as friends would be scored a 2 on the scale, whereas respondents who would accept these group members as citizens of the country but no further would be scored a 5, indicating greater social distance. Results from multiple respondents are then averaged to compare mean social distance scores for different groups or changes in social distance over time. 
The Bogardus scale provides a powerful tool for measuring an important social phenomenon. Yet despite its great utility, the traditional scale has a number of drawbacks that are inherent in all Guttman scales. [See Clogg and Sawyer (1981) for a summary.] In the section that follows, we will demonstrate these and other shortcomings by comparing it to a multidimensional Social Distance Intensity Score (iScore). We argue that this new approach provides improved results.

\section{SOCIAL DISTANCE INTENSITY SCORE}

The intensity score (iScore) is an intensifying measurement, which multiplicatively combines the Bogardus scale and the Likert (1932) scale in a unique way that provides better results than the traditional method. As illustrated in the example questionnaire in Figure 1 below, the iScore registers the self-disclosed perceived social distance scores of the Bogardus scale, but it provides a finer grained and more nuanced picture of the respondents' sentiments by additionally employing Likert responses.

Circle the number that best describes your response to these statements according to the following scale:

1=Strongly agree; 2 =agree; $3=$ Neither agree or Disagree; $4=$ Disagree; $5=$ Strongly disagree

I would be willing to accept [group member] as a close relative by marriage

I would be willing to accept [group member] as a close personal friend

I would be willing to accept [group member] as a neighbor on the same street

I would be willing to accept [group member] as a coworker

I would be willing to accept [group member] as a citizen in my country

I would be willing to accept [group member] as a visitor in my country

Figure 1 iScore example survey. *Survey statement reads, "I would exclude group member from my country.” The word "not" is added here to make all Likert responses run in the same direction.

The scale is scored utilizing the rank order from the Bogardus scale as a multiplier to the Likert responses for each item. For example, the Bogardus 
statement "I would be willing to accept [group member] as a close relative by marriage" indicates the lowest level of social distance and is therefore ranked 1 in the original Bogardus scale. This 1 is then multiplied by the Likert score given by the respondent. Thus, a respondent who indicates that she strongly agrees that she would accept members of a group as relatives by marriage would receive a score of $1(1 \times 1)$ for that item. Excluding a group member from the country indicates the highest level of social distance and is ranked 7. Thus, someone who strongly disagrees that he or she would not exclude someone from a certain group (that is to say the respondent would indeed exclude members of that group from the country) would receive a high social distance score of $35(7 \times 5)$ for that item. The totals for the responses to each item are added to give a total iScore for a given group. The range of the total iScore is 28-140. Like the Bogardus score, mean iScores can then be used to compare mean social distances for the groups in question.

It should be noted that, while it is still relatively simple, using the iScore creates some additional cognitive work for survey respondents because it asks them to assess their level of agreement or disagreement on each item. Analytically, researchers must undertake a few more steps to compute the iScore, but the process is not onerous and, as we will demonstrate below, the improved results are worth the extra effort.

\section{METHODS}

To demonstrate the normal function of the Bogardus scale compared with the enhanced function of the iScore, we created 30 sample respondents, who provided different answers to the questions listed in Figure 1. The respondents ranged from those with very high social distance (antipathy) to very low social distance (affinity), with a full middle range of responses (ambivalent). The various response sets were then used to create both a traditional Bogardus score and an iScore. Respondents who answered "Strongly agree" or "Agree" were coded "Yes" for each of the Bogardus questions. Those who answered "Disagree" or "Strongly disagree" were coded "No." We had to choose whether to interpret the "Neither agree nor disagree" Likert response as a "Yes" or "No" response in the original Bogardus scale and elected to interpret the Likert " 3 " as "No." (See respondent "Ambivalent 8 " in Table 1 below for an example.) 
Table 1 Bogardus and iScore comparisons.

\begin{tabular}{|c|c|c|c|c|c|c|c|c|c|c|c|c|c|c|c|c|c|c|c|}
\hline \multirow[t]{2}{*}{ Respondent } & \multicolumn{3}{|c|}{$\begin{array}{l}7 \\
\text { Not exclude from my } \\
\text { country }\end{array}$} & \multicolumn{3}{|c|}{$\begin{array}{l}6 \\
\text { Visitor in my country }\end{array}$} & \multicolumn{3}{|c|}{$\begin{array}{l}5 \\
\text { Citizen in my country }\end{array}$} & \multicolumn{3}{|c|}{$\begin{array}{l}4 \\
\text { Co-worker }\end{array}$} & \multicolumn{3}{|c|}{$\begin{array}{l}3 \\
\text { Neighbor on my street }\end{array}$} & \multicolumn{3}{|c|}{$\begin{array}{l}2 \\
\text { Close friend }\end{array}$} & \multirow{2}{*}{$\begin{array}{l}1 \\
\text { Close } \\
\text { B }\end{array}$} \\
\hline & B & $1-5$ & iScore & B & $1-5$ & iScore & B & $1-5$ & iScore & B & $1-5$ & iScore & B & $1-5$ & iScore & B & $1-5$ & iScore & \\
\hline Affinity 1 & Yes & 1 & 7 & Yes & 1 & 6 & Yes & 1 & 5 & Yes & 1 & 4 & Yes & 1 & 3 & Yes & 1 & 2 & Yes \\
\hline Affinity 2 & Yes & 1 & 7 & Yes & 1 & 6 & Yes & 1 & 5 & Yes & 1 & 4 & Yes & 1 & 3 & Yes & 1 & 2 & Yes \\
\hline Affinity 3 & Yes & 1 & 7 & Yes & 1 & 6 & Yes & 1 & 5 & Yes & 1 & 4 & Yes & 1 & 3 & Yes & 2 & 4 & Yes \\
\hline Affinity 4 & Yes & 1 & 7 & Yes & 1 & 6 & Yes & 1 & 5 & Yes & 1 & 4 & Yes & 2 & 6 & Yes & 2 & 4 & Yes \\
\hline Affinity 5 & Yes & 1 & 7 & Yes & 1 & 6 & Yes & 1 & 5 & Yes & 2 & 8 & Yes & 2 & 6 & Yes & 2 & 4 & Yes \\
\hline Affinity 6 & Yes & 1 & 7 & Yes & 1 & 6 & Yes & 2 & 10 & Yes & 2 & 8 & Yes & 2 & 6 & Yes & 2 & 4 & Yes \\
\hline Affinity 7 & Yes & 1 & 7 & Yes & 2 & 12 & Yes & 2 & 10 & Yes & 2 & 8 & Yes & 2 & 6 & Yes & 2 & 4 & Yes \\
\hline $\begin{array}{l}\text { Ambivalent } \\
1\end{array}$ & Yes & 2 & 14 & Yes & 2 & 12 & Yes & 2 & 10 & Yes & 2 & 8 & Yes & 2 & 6 & Yes & 2 & 4 & Yes \\
\hline $\begin{array}{l}\text { Ambivalent } \\
2\end{array}$ & Yes & 2 & 14 & Yes & 2 & 12 & Yes & 2 & 10 & Yes & 2 & 8 & Yes & 2 & 6 & Yes & 2 & 4 & No \\
\hline $\begin{array}{l}\text { Ambivalent } \\
3\end{array}$ & Yes & 2 & 14 & Yes & 2 & 12 & Yes & 2 & 10 & Yes & 2 & 8 & Yes & 2 & 6 & No & 3 & 6 & No \\
\hline $\begin{array}{l}\text { Ambivalent } \\
4\end{array}$ & Yes & 2 & 14 & Yes & 2 & 12 & Yes & 2 & 10 & Yes & 2 & 8 & No & 3 & 9 & No & 3 & 6 & No \\
\hline $\begin{array}{l}\text { Ambivalent } \\
5\end{array}$ & Yes & 2 & 14 & Yes & 2 & 12 & Yes & 2 & 10 & No & 3 & 12 & No & 3 & 9 & No & 3 & 6 & No \\
\hline $\begin{array}{l}\text { Ambivalent } \\
6\end{array}$ & Yes & 2 & 14 & Yes & 2 & 12 & No & 3 & 15 & No & 3 & 12 & No & 3 & 9 & No & 3 & 6 & No \\
\hline $\begin{array}{l}\text { Ambivalent } \\
7\end{array}$ & Yes & 2 & 14 & No & 3 & 18 & No & 3 & 15 & No & 3 & 12 & No & 3 & 9 & No & 3 & 6 & No \\
\hline $\begin{array}{l}\text { Ambivalent } \\
8\end{array}$ & No & 3 & 21 & No & 3 & 18 & No & 3 & 15 & No & 3 & 12 & No & 3 & 9 & No & 3 & 6 & No \\
\hline $\begin{array}{l}\text { Ambivalent } \\
9\end{array}$ & No & 3 & 21 & No & 3 & 18 & No & 3 & 15 & No & 3 & 12 & No & 3 & 9 & No & 3 & 6 & No \\
\hline $\begin{array}{l}\text { Ambivalent } \\
10\end{array}$ & No & 3 & 21 & No & 3 & 18 & No & 3 & 15 & No & 3 & 12 & No & 3 & 9 & No & 4 & 8 & No \\
\hline $\begin{array}{l}\text { Ambivalent } \\
11\end{array}$ & No & 3 & 21 & No & 3 & 18 & No & 3 & 15 & No & 3 & 12 & No & 4 & 12 & No & 4 & 8 & No \\
\hline
\end{tabular}




\begin{tabular}{|c|c|c|c|c|c|c|c|c|c|c|c|c|c|c|c|c|c|c|c|}
\hline \multirow[t]{2}{*}{ Respondent } & \multicolumn{3}{|c|}{$\begin{array}{l}7 \\
\text { Not exclude from my } \\
\text { country }\end{array}$} & \multicolumn{3}{|c|}{$\begin{array}{l}6 \\
\text { Visitor in my country } \\
\end{array}$} & \multicolumn{3}{|c|}{$\begin{array}{l}5 \\
\text { Citizen in my country }\end{array}$} & \multicolumn{3}{|c|}{$\begin{array}{l}4 \\
\text { Co-worker }\end{array}$} & \multicolumn{3}{|c|}{$\begin{array}{l}3 \\
\text { Neighbor on my street }\end{array}$} & \multicolumn{3}{|c|}{$\begin{array}{l}2 \\
\text { Close friend }\end{array}$} & \multirow{2}{*}{$\begin{array}{l}1 \\
\text { Close } \\
\text { B }\end{array}$} \\
\hline & B & $1-5$ & iScore & B & $1-5$ & iScore & B & $1-5$ & iScore & B & $1-5$ & iScore & B & $1-5$ & iScore & B & $1-5$ & iScore & \\
\hline $\begin{array}{l}\text { Ambivalent } \\
12\end{array}$ & No & 3 & 21 & No & 3 & 18 & No & 3 & 15 & No & 4 & 16 & No & 4 & 12 & No & 4 & 8 & No \\
\hline $\begin{array}{l}\text { Ambivalent } \\
13\end{array}$ & No & 3 & 21 & No & 3 & 18 & No & 4 & 20 & No & 4 & 16 & No & 4 & 12 & No & 4 & 8 & No \\
\hline $\begin{array}{l}\text { Ambivalent } \\
14\end{array}$ & No & 3 & 21 & No & 4 & 24 & No & 4 & 20 & No & 4 & 16 & No & 4 & 12 & No & 4 & 8 & No \\
\hline Antipathy 1 & No & 4 & 28 & No & 4 & 24 & No & 4 & 20 & No & 4 & 16 & No & 4 & 12 & No & 4 & 8 & No \\
\hline Antipathy 2 & No & 4 & 28 & No & 4 & 24 & No & 4 & 20 & No & 4 & 16 & No & 4 & 12 & No & 4 & 8 & No \\
\hline Antipathy 3 & No & 4 & 28 & No & 4 & 24 & No & 4 & 20 & No & 4 & 16 & No & 4 & 12 & No & 5 & 10 & No \\
\hline Antipathy 4 & No & 4 & 28 & No & 4 & 24 & No & 4 & 20 & No & 4 & 16 & No & 5 & 15 & No & 5 & 10 & No \\
\hline Antipathy 5 & No & 4 & 28 & No & 4 & 24 & No & 4 & 20 & No & 5 & 20 & No & 5 & 15 & No & 5 & 10 & No \\
\hline Antipathy 6 & No & 4 & 28 & No & 4 & 24 & No & 5 & 25 & No & 5 & 20 & No & 5 & 15 & No & 5 & 10 & No \\
\hline Antipathy 7 & No & 4 & 28 & No & 5 & 30 & No & 5 & 25 & No & 5 & 20 & No & 5 & 15 & No & 5 & 10 & No \\
\hline Antipathy 8 & No & 5 & 35 & No & 5 & 30 & No & 5 & 25 & No & 5 & 20 & No & 5 & 15 & No & 5 & 10 & No \\
\hline Ambivalent & Yes & 1 & 7 & Yes & 1 & 6 & No & 4 & 20 & Yes & 2 & 8 & No & 3 & 9 & Yes & 2 & 4 & No \\
\hline
\end{tabular}

${ }^{a}$ Ambivalent 16 represents just 1 potential set of responses that do not follow the ordered assumptions of Bogardus. 
These same responses were also used to create iScores. The resulting scores were then used to compare the outcomes for the two scales. Results from this simple comparison are displayed to show the advantages of using the iScore over the traditional Bogardus scale.

\section{RESULTS}

Table 1 shows the results of our comparisons between the two methods. At the very top are listed column headings for each Bogardus social distance statement. These headings also include a number indicating the social distance score, which serves as the multiplier for the iScore calculation. Below these main headings are three columns listing results for the 30 sample respondents that we have created. The first sub-heading " $B$ " lists the binary Yes/No responses that make up the original Bogardus scale. The second subheading lists the 1-5 Likert responses. The third subheading under each main column provides the iScore, which is calculated by multiplying the Likert score by the social distance score that is listed at the top of each main column. Simple addition across the columns marked "B," where $\mathrm{No}=1$ and Yes $=0$ yields social distance scores between 0 and 7 on the Bogardus scale. Similarly, adding results across the "iScore" columns generates a total iScore, which ranges from a low of 28 to a high social distance score of 140 . The columns to the far right of the table display the Bogardus scores and iScores for each respondent.

The differences between these scales are most clearly demonstrated through a graphic representation of the results. In Figure 2, below, we have normalized the Bogardus and iScore scales and placed them over top of each other for direct comparison.
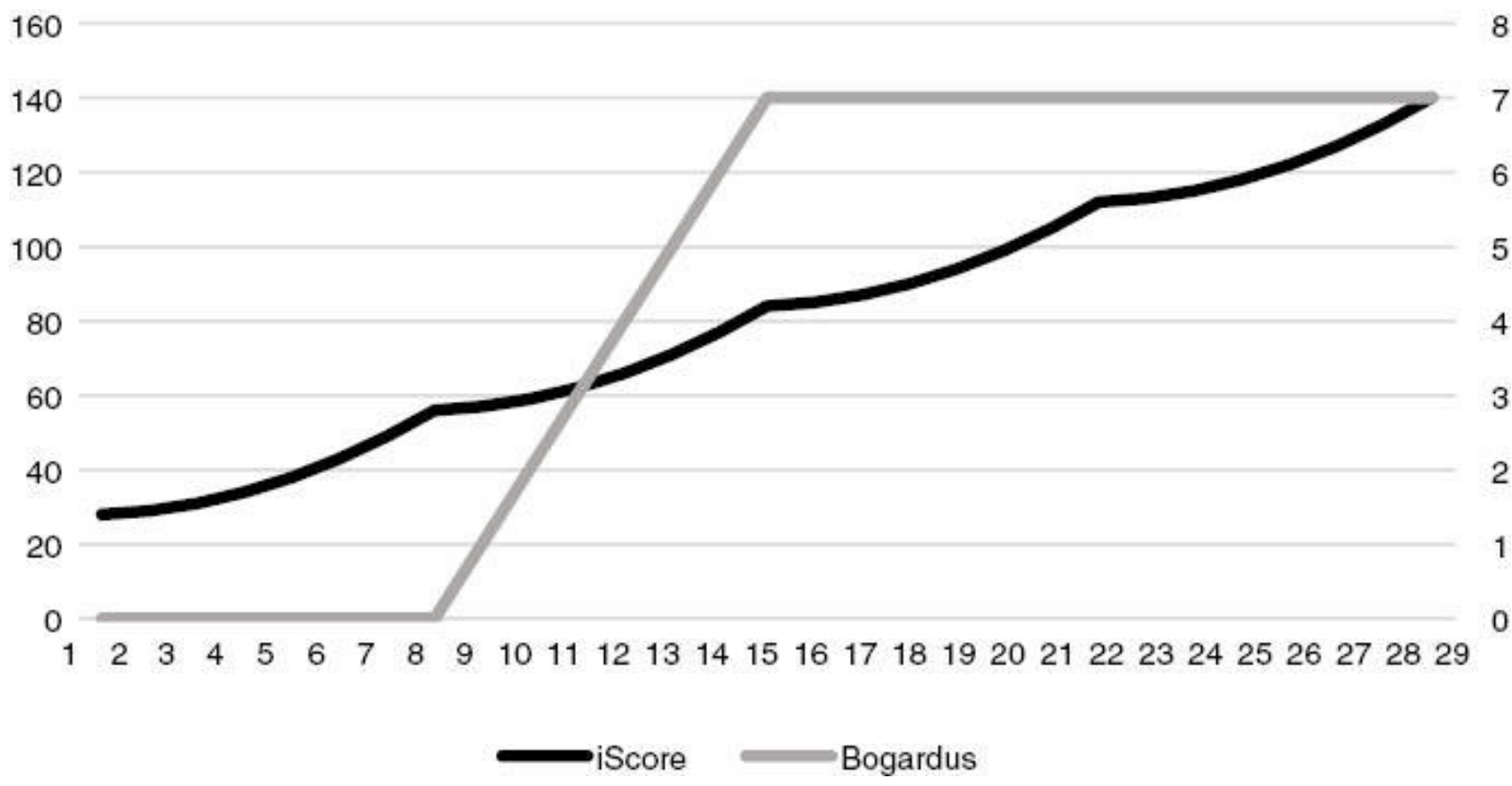

Figure 2 Bogardus and iScore compared 
The first thing to note is that, despite their varied attitudes, Bogardus does not differentiate between respondents 1-8 on the left end of the scale and between respondents 14-29 at the right end of the scale. By contrast, the iScore highlights differences across the board. The Bogardus scale is only sensitive to differences between the respondents that we have labeled Ambivalents 1-8. The 21 others, who have varying ranges of affinity on one end of the scale and antipathy on the other, are all treated the same by Bogardus. The two graph lines in Figure 2 clearly demonstrate the improved precision and granularity of the iScore.

While one could convincingly argue that Affinity 1-7 and Antipathy 1-8 are correctly identified by Bogardus (the only difference being the degree to which they agree or disagree with the statements), we would argue that Ambivalents 9-14 fit in a different category. Ambivalent 9, for instance, who would not accept members of the group as close relatives, but is on the fence about the other responses, is given a 7 , indicating the highest social distance on the Bogardus scale. This outcome is the result of our decision to code " 3 's" as "No," but had we coded them as "Yes" Ambivalent 9 would have received a total score of " 1 " on the Bogardus scale, suggesting very little social distance. This highlights another advantage of the iScore over Bogardus. Instead of forcing choices, it is sensitive enough to deal with respondent ambivalence and place such responses meaningfully on the scale.

Table 1 demonstrates a final, and perhaps the most important, advantage of the iScore. As noted above, the Bogardus scale is a Guttman binary scale that is predicated on the rank-order notion that those who affirmatively respond to one item of the scale will also respond affirmatively to the items before it. So a person who would accept a member from a certain group as a citizen would naturally be assumed to be willing to accept them as a visitor to the country and would not exclude them from the country. While this assumption makes sense in most circumstances, it cannot be applied to all social relationships. Ambivalent 16, at the very bottom of Table 1, is an example of a person who does not provide such ordered responses. Her answers indicate that she would accept a member of a certain group as a co-worker and friend and possibly as a neighbor, but definitely not as a citizen. This is a very plausible response. (A farmer may want Mexicans to work with her in her fields and she may even befriend them, but she may not want them to become citizens.) Although it is common for people to hold views that diverge from the ordered scale, Bogardus cannot accommodate them (hence the question marks on Ambivalent 16 in Table 1). The nuanced nature of the iScore allows it to effectively address this issue, which has long been identified as a short-coming of Guttman scales (Clogg and Sawyer 1981).

Some may argue that these advantages of the iScore are not sufficient to warrant replacing the Bogardus scale because ambivalent and non-ordered social distance responses are not a regular feature of American social life. It 
is difficult to make this claim because most social distance research has been done with the Bogardus scale, which is not sensitive to these attitudes. The authors recently conducted a social distance study using the iScore to measure the attitudes of students on their college campus. Using a modified scale that included questions about accepting people from different ethnic and racial groups as partners in marriage, as roommates, as friends, as professors and as students at my college, we found that $36 \%$ of our 279 respondent gave a " 3 " (ambivalent) response to at least one of the questions. (Most were on the right side of the scale, unsure if they would marry someone from this ethnic or racial group.) Six percent were highly ambivalent, providing a " 3 " response to two or more of the questions. Additionally, we found that $9 \%$ of our sample gave non-ordered responses. For instance, some would gladly accept a person from a particular group as a roommate or a friend, but they were unsure or unwilling to have them as a professor. A number of others said they would be open or very open to marrying someone from a certain group, but they were unsure about having them for a roommate. While this study used a small sample from one college employing a modified Bogardus scale, it does suggest that ambivalent and non-ordered responses may be more prevalent than assumed and thus are worth investigating using a scale like the iScore.

\section{CONCLUSION}

For many years, the Bogardus scale has been the standard instrument for social distance research. As such, it has contributed greatly to our understanding of prejudice and intergroup relations. However, as we have demonstrated above, the scale has a number of shortcomings that can be overcome with the use of an intensity scale. Side-by-side comparisons of the Bogardus and iScore scales across a range of possible responses show that the iScore is more precise, sensitive, and nuanced than the traditional scale. The iScore registers important differences at either end of the scale that Bogardus completely misses. It can also account for respondent ambivalence and for responses that do not fit the rank-ordered assumptions of the Bogardus scale. Because it provides a number of important advantages, we argue that future social distance studies should be done using the iScore to determine if our understanding of this important phenomenon can be improved by using a more nuanced scale.

\section{ACKNOWLEDGEMENT}

The authors wish to thank Walter Brath for his contributions during the early stages of this project and Cindy Mather for her help in preparing the manuscript. 


\section{REFERENCES}

Bogardus, E.S. 1926. "Social Distance in the City." Proceedings and Publications of the American Sociological Society 20 (1926): 40-46.

- - 1959. Social Distance. Los Angeles, CA: University of Southern California Press.

Clogg, C.C., and D.O. Sawyer. 1981. "A Comparison of Alternative Models for Analyzing the Scalability of Response Patterns.” Sociological Methodology 12 (1981): 240-80.

Ethington, P.J. 1997. “The Intellectual Construction of 'Social Distance': Toward a Recovery of Georg Simmel's Social Geometry." CyberGeo: European Journal of Geography.

http://cybergeo.revues.org/227.

Guttman, L. 1950. “The Basis for Scalogram Analysis.” In Measurement and Prediction. The American Soldier, edited by S.A. Stouffer, L. Guttman, E.A. Suchman, P.F. Lazarsfeld, S.A. Star, and J.A. Clausen. Vol. IV. New York: Wiley.

Halperin, E., A. Pedahzur, and D. Canetti-Nisim. 2007. "Psychoeconomic Approaches to the Study of Hostile Attitudes toward Minority Groups: A Study among Israeli Jews.” Social Science Quarterly 88 (1): 177-98.

Likert, R. 1932. "A Technique for the Measurement of Attitudes.” Archives of Psychology 140 (1932): 1-55.

Parrillo, V.N., and C. Donoghue. 2005. "Updating the Bogardus Social Distance Studies: A New National Survey.” The Social Science Journal 42 (2): 257-71.

Weaver, C.N. 2008. "Social Distance as a Measure of Prejudice among Ethnic Groups in the United States.” Journal of Applied Social Psychology 38 (3): 779-95. 